\title{
DIÁLOGO ENTRE OS SABERES: AS RELAÇÕES ENTRE SENSO COMUM, SABER POPULAR, CONHECIMENTO CIENTÍFICO E ESCOLAR
}

\author{
Eneida Orbage de Britto Taquary ${ }^{*}$
}

\section{Resumo}

Discutem-se, neste artigo, as relações entre saber científico, popular e escolar e senso comum. Para tanto, retomam-se perspectivas históricas, com foco nos estudos de Kuhn sobre as revoluções científicas, relacionados ao que ele chamou de crise entre os paradigmas existentes. São, também, observadas características e definições dos demais saberes e do senso comum, para, por fim, se compararem uns aos outros em suas limitações. Admitindo-se que a destruição dos paradigmas é condição para a construção do conhecimento científico, conclui-se que o saber científico se constrói em consonância com os outros saberes.

Palavras-chave: Saberes. Paradigmas. Desenvolvimento científico.

\section{Introdução}

A proposta do presente trabalho refere-se a discutir, em breves linhas, o diálogo entre os saberes. Não é atualíssima, mas, sempre, estará na pauta do dia, porque a vida humana e as relações daí advindas, seja no campo social, cultural, econômico, religioso ou jurídico, exigem que não se precipite

\footnotetext{
* Professora de Direito Penal, mestre em direito das relações internacionais. Delegada da Polícia Civil do Distrito Federal. Artigo elaborado na disciplina Usos da Mediação e Cidadania, ministrada pelo Professor Dr. Luis Alberto Warat, apresentada como requisito parcial à conclusão da disciplina no Curso de Doutorado em Direito da Universidade de Brasília.
} 
na delimitação do que é o saber popular e do que é o saber científico. Em geral, despreza-se o primeiro em exaltação ao segundo, apesar de, não raras vezes, o saber popular determinar a investigação para se precisar o saber científico.

Nesse sentido, afirma Simon Schwartzman que

a principal contribuição da moderna antropologia e sociologia do conhecimento, marcada pelos trabalhos pioneiros de Karin Knorr e Bruno Latour, entre outros, foi o rompimento da demarcação rígida que se supunha existir entre o conhecimento 'verdadeiro', científico, e o conhecimento popular, não científico e, por isto mesmo, tratado frequentemente como ingênuo ou errôneo ${ }^{1}$.

Conclui, afirmando que o conhecimento cientifico nem é “tão seguro e verdadeiro assim, nem o conhecimento popular é necessariamente errôneo"2.

Essa preocupação entre o real sentido da verdade, se científica ou não, remonta à Antiguidade. Sófocles, em suas peças, retrata com fidedignidade a situação conflituosa da busca da verdade, depois tão bem retratada por Foucault, em A Verdade e as Formas Jurídicas ${ }^{3}$.

Note-se que a preocupação com a busca do conhecimento e com as bases em que ele se assenta foi, de forma precisa, demonstrada por Thomas S. Kuhn, em A Estrutura das Revoluções Científicas ${ }^{4}$, obra resultante dos estudos a respeito do que o autor denominou crise entre os paradigmas

\footnotetext{
${ }^{1}$ SCHWARTZMAN, Simon. Saberes científicos e saberes populares. Disponível em: <www.schwartzman.org.br/simon/ABA.htm>. Acesso em: 29 dez. 2006. Apresentado na Reunião Anual da Associação Brasileira de Antropologia, Vitória, abril de 1998.

2 Ibidem.

${ }^{3}$ FOUCAULT, M. A verdade e as formas jurídicas. Rio de Janeiro: Nau, 1999. p. 32.

${ }^{4}$ KUHN, Thomas S. A estrutura das revoluções científicas. Traduzido por Beatriz Vianna Boeira; Nelson Boeira. Revisão Alice Kyoko Myashiro. Produção Plínio Martins Filho. São Paulo: Perspectiva, 1982. (Coleção debates). Título original: The structure of scientific revolutions.
} 
existentes, considerando paradigma "as realizações científicas universalmente reconhecidas que, durante algum tempo, fornecem problemas e soluções modelares para uma comunidade de praticantes de uma ciência”, e as implicações no seu conceito, sua natureza e desenvolvimento. Reavaliaramse, no citado livro, dois pontos: o primeiro, referente ao quando e por quem cada fato, teoria ou lei científica contemporânea foi descoberto ou inventado; e o segundo, relativo à descrição e à explicação dos amontoados de erros, mitos e superstições gerados por aquelas teorias e leis científicas, que impediam o acúmulo de conhecimento, isto é, o progresso da ciência.

Segundo Kuhn (1982), os amigos mereciam uma explicação concernente ao porquê tanto de sua mudança da ciência (física) para a História da Ciência quanto, certamente, do estudo da revolução científica, designação atribuída por ele a "aqueles episódios de desenvolvimento nãocumulativo, nos quais um paradigma mais antigo é total ou parcialmente substituído por um novo, incompatível com o anterior”,

Essa revolução científica somente é gerada pela crise que se estabelece quando se detecta um funcionamento defeituoso que se afigura como

um sentimento crescente, também seguidamente restrito a uma pequena subdivisão da comunidade científica, de que o paradigma existente deixou de funcionar adequadamente na exploração de um aspecto da natureza, cuja exploração fora anteriormente dirigida pelo paradigma ${ }^{7}$.

O autor Thomas S. Kuhn elaborou seu livrou ao abandonar o curso de pós-graduação de Física Teórica, do qual era aluno com dissertação

\footnotetext{
${ }^{5}$ KUHN, Thomas S. A estrutura das revoluções científicas. Traduzido por Beatriz Vianna Boeira; Nelson Boeira. Revisão Alice Kyoko Myashiro. Produção Plínio Martins Filho. São Paulo: Perspectiva, 1982. p. 13. (Coleção debates). Título original: The structure of scientific revolutions

${ }^{6}$ Ibidem, p. 125.

${ }^{7}$ Ibidem, p. 126.
} 
já definida, após participar de um curso experimental de ciência física para não cientistas, ocasião em que foi introduzido no estudo da História da Ciência. Passou pela Univesidade de Harvad, onde estudou escritos de Alexandre Koyré, Émile Meyerson, Helène Meztezer e Annelise Maier e, também, Jean Piaget. Depois de uma série de conferências para o Lowel Institute de Boston, já em 1952, passou a lecionar a disciplina, e o fez durante uma década, o que ensejou a primeira publicação da obra em 1962 e a segunda, em 1969, com algumas modificações, dado o aperfeiçoamento das idéias do autor.

Ele explora a natureza do progresso científico como uma "sucessão de períodos ligados à tradição e pontuados por rupturas nãocumulativas”8. A descoberta científica leva em conta o problema, definido pelo conhecimento e por técnicas, que será resolvido com sucesso, à medida que se tracem os objetivos, se utilizem instrumentos próprios e se observe o que ocorre à sua volta.

A contribuição dos estudos de Kuhn reside no fato de que não há construção do conhecimento científico sem que se destruam os paradigmas já estabelecidos, visando à “articulação” desses já existentes.

Destaca-se, de modo marcante, na obra, a estrutura traçada pelo autor para que o pesquisador chegue ao conhecimento científico, que irá brotar após um período de turbulência, chamado por ele de revolução científica.

É necessário, segundo Kuhn, para se obter o progresso científico, sempre partir de modelos concretos, os paradigmas, bem como dos testes, instrumentos, leis e teorias propostos em seus escritos.

${ }^{8}$ KUHN, Thomas S. A estrutura das revoluções científicas. Traduzido por Beatriz Vianna Boeira; Nelson Boeira. Revisão Alice Kyoko Myashiro. Produção Plínio Martins Filho. São Paulo: Perspectiva, 1982. p. 255. (Coleção debates). Título original: The structure of scientific revolution. 
Nessa perspectiva, para explicar a transformação do pensamento científico, mediante o estabelecimento de um novo paradigma, ele trabalha com os conceitos de anomalias, crise, descobertas, invenções, enfim, de progresso científico. Estabelece, finalmente, que três resultados podem advir das crises entre os modelos concretos, que são colocados em evidência como superados para resolver aqueles novos problemas: o paradigma questionado mostra-se suficiente para a resolução do problema; não é suficiente, mas não aflora outro que venha a solucionar a questão; ou, então, surge um candidato a paradigma como fórmula inovadora de resolução da crise evidenciada entre ele e o anterior, que será destruído, seguindo-se a isso a resistência da comunidade científica em aceitá-lo.

O estudo da origem da ciência conduz à mudança de paradigmas desta, indicando sua reorganização, modificando princípios, reconstruindo teorias e métodos, originando um mundo diferente, “como se a comunidade profissional tivesse sido subitamente transportada para um novo planeta"9.

\section{Distinção entre senso comum, saber popular e científico}

Consoante o pensamento marcante de Thomas Kuhn, o prérequisito para o estudo do desenvolvimento científico e, logo, para a realização da ciência normal (entendida como a pesquisa firmemente baseada em uma ou mais realizações científicas passadas, que proporcionam os fundamentos para sua prática posterior) ${ }^{10}$ é o conhecimento dos paradigmas, isto é, dos fundamentos extraídos dos mesmos modelos concretos que são compartilhados e que geram o comprometimento com as mesmas regras e

\footnotetext{
${ }^{9}$ KUHN, Thomas S. A estrutura das revoluções científicas. Traduzido por Beatriz Vianna Boeira; Nelson Boeira. Revisão Alice Kyoko Myashiro. Produção Plínio Martins Filho. São Paulo: Perspectiva, 1982. p. 145. (Coleção debates). Título original: The structure of scientific revolutions.

${ }^{10}$ Ibidem, p. 29.
} 
padrões para o desenvolvimento da prática científica. Para esse teórico, o diálogo entre o conhecimento passado e a sua prática posterior é que ensejará a compreensão da essência dos mesmos conteúdos que determinarão a construção de novos saberes. Há continuidade na compreensão dos saberes e comprometimento para a realização de outros. O saber popular e o senso comum são ponto de partida para, depois de compartilhados, serem geradores dos fundamentos que desencadearão o processo de construção do saber científico.

Considerando-se outro ponto de vista, Alice Ribeiro Casimiro Lopes afirma que senso comum, é a forma de expressão do saber popular, a maneira de as camadas populares conceberem e interpretarem o mundo: "Desprezá-lo seria menosprezar o saber popular e qualquer forma de saber não científico"11.

Não se pode, todavia, superestimar o saber popular, pois, segundo Foucault, a ciência segue regras estabelecidas pelo conjunto da comunidade científica, segue regras preestabelecidas de construção de proposições $^{12}$.

De acordo com Boaventura Santos, o senso comum é um pensamento necessariamente conservador e fixista. Para se chegar à ciência, ter-se-ia que romper com o conhecimento comum. Mas a ciência jamais se liberta de todos os preconceitos que advêm do senso comum, que, por sua vez, se prende ao aparente, ao genérico e às experiências do cotidiano ${ }^{13}$.

Assim, para o autor, há necessidade de uma tradução entre os saberes. Essa tradução assume a forma de uma hermenêutica diatópica, que

${ }^{11}$ LOPES, Alice Cassimiro. Saberes em relação aos quais o conhecimento escolar se constituiu. In: Conhecimento escolar: ciência e cotidiano. Rio de Janeiro: Ed. UERJ, 1999. p. 103- 155.

${ }^{12}$ FOUCAULT, M. Microfísica do poder. Rio de Janeiro: Graal, 1988. p. 43

13 SANTOS, Boaventura de Sousa. Introdução a uma ciência pós-moderna. Porto: Afrontamento, 2002. p. 22. 
consiste na "interpretação de duas ou mais culturas com vistas a identificar preocupações isomórficas entre elas e as diferentes respostas que oferecem a elas"14.

Daí, o autor Kosik afirmar que o conhecimento comum, advindo do senso comum, se detém em fenômenos evidentes e imediatos - 0 mundo da pseudoconcreticidade ${ }^{15}$.

Vê-se, portanto, que o senso comum é transclassista, porque alcança a todos indistintamente, independente de classe social ou econômica. O senso comum caracteriza-se, pois, pela sua universalidade, fazendo com que haja a manutenção dos valores e das idéias, enfim, da estrutura da sociedade, em seu cotidiano. É ele que orienta a sociedade, dado seu caráter de universalidade e uniformidade, perante sociedades diversas.

O saber popular, ao contrário do senso comum, é específico e diverso, à medida que visa não à sociedade como um todo, mas aos diversos grupos que a compõem. Está a margem das instituições formais, não lhe emprestando o poder e a legitimidade do saber aceito.

A relação entre o senso comum e o saber popular é ideológica, motivo pelo qual não se pode desvalorizar o saber popular e enaltecer o senso comum, sob pena de falsa construção do conhecimento. O senso comum e o saber popular não obedecem às regras preestabelecidas ou proposições oriundas da comunidade científica, o que caracterizará o saber científico.

O saber científico não pode e não deve soerguer-se ante o saber popular e escolar, pois o saber escolar, como fonte geradora da produção do conhecimento, se consolida com base no questionamento e na discussão dos saberes firmados pela sociedade e daqueles que foram produzidos por

\footnotetext{
${ }^{14}$ SANTOS, Boaventura de Sousa. Toward a new common sense; law, science and politics in the paradigmatic transition. Nova Iorque: Routlegde, 1995. p. 340.

${ }^{15}$ KOSIK, K. A dialética do concreto. Rio de Janeiro: Paz e Terra. 1976. p- 11-30.
} 
instituições legitimadas para tanto, de forma que viabilize a construção de novos saberes, transformadores da vida daqueles que podem interferir na elaboração do conhecimento; terceiros alheios ao processo de elaboração do conhecimento, determinando a transformação social.

\section{Referências}

FOUCAULT, M. A verdade e as formas jurídicas. Rio de Janeiro: Nau, 1999.

FOUCAULT, M. Microfísica do poder. Rio de Janeiro: Graal, 1988.

KOSIK, K. A dialética do concreto. Rio de Janeiro: Paz e Terra. 1976.

KUHN, Thomas S. A estrutura das revoluções científicas. Traduzido por Beatriz Vianna Boeira; Nelson Boeira. Revisão Alice Kyoko Myashiro. Produção Plínio Martins Filho. São Paulo: Perspectiva, 1982. (Coleção debates). Título original: The structure of scientific revolutions.

LOPES, Alice Cassimiro. Saberes em relação aos quais o conhecimento escolar se constituiu. In: . Conhecimento escolar: ciência e cotidiano. Rio de Janeiro: Ed. UERJ, 1999. p. 103- 155.

SANTOS, Boaventura de Sousa. Introdução a uma ciência pós-moderna. Porto: Afrontamento, 2002.

SANTOS, Boaventura de Sousa. Toward a new common sense; law, science and politics in the paradigmatic transition. Nova Iorque: Routlegde, 1995.

SCHWARTZMAN, Simon. Saberes científicos e saberes populares. Disponível em: <www.schwartzman.org.br/ simon/ABA.htm>. Acesso em: 29 dez. 2006. Apresentado na Reunião Anual da Associação Brasileira de Antropologia, Vitória, abril de 1998. 